\title{
Analytical Solution of Heat Distribution Inside a Printed Circuit Board During Vapour Phase Soldering
}

\author{
Dániel Straubinger, István Bozsóki, Balázs Illés, Attila Géczy \\ Department of Electronics Technology, Budapest University of Technology and Economics, Budapest, Hungary \\ daniel.straubinger@ett.bme.hu
}

\begin{abstract}
Vapour Phase Soldering (VPS) is a reflow soldering method, which is under investigation from many aspects, due to its unique heat transfer mechanism: condensation-based heating. To maintain and improve the quality of the solder joints the heat transient and distribution of a given assembly must be known paramters. In this paper, one dimensional modelling of heat distribution within the thickness of a Printed Circuit Board (PCB) is investigated. Heat transient is calculated for the VPS process at different positions within the PCB. The results are calculated in the confines of VPS, where heat transfer occurs on both sides of the $P C B$ due to the occurring filmwise condensation. The results present information about temperature distribution along the thickness of the PCB in the time domain. This data can be incorporated into more complex simulation approaches and profile predicting algorithms for better temperature control.
\end{abstract}

\section{INTRODUCTION}

Vapour phase soldering (VPS) is an alternative reflow soldering method to the most commonly used infra-radiation (IR) and convection reflow soldering. VPS has several advantages due to its stable soldering temperature which prevents overheating, its inert atmosphere and the reliability of the solder joints [1]. The standard VPS process is illustrated in Fig. 1. The assembly is lowered to the saturated vapour of Galden PFPE type liquid [2], which condenses onto the surface with filmwise condensation; then latent heat is released due to the phase change of the vapour which is transferred to the assembly [3].

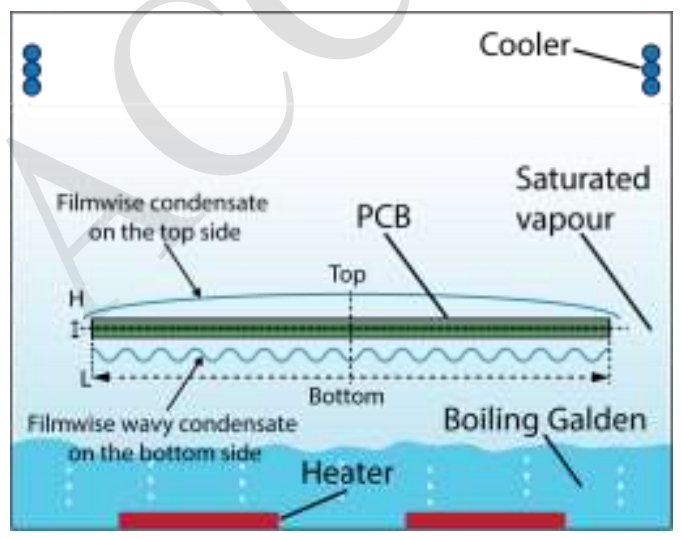

Fig. 1. Usual VPS setup with PCB and highlighted filmwise condensation
Besides the advantageous properties of Galden,the process is affected by several other parameters, such as the state and flow of the condensation layer [4], heating power, volume of the saturated vapour and surface dimensions. VPS also can be used with vacuum conditions; the solder joint quality was investigated from several aspects [5,6,7] with this technology. Applying vacuum can enhance solder joint quality and reduce the number of voids.

To achieve the best possible soldering quality, the even the heat distribution and well controlled thermophysical parameters are necessary. The optimal soldering profile and heating factor have considerable effect on the solder joint quality [8]. Besides simulation and modelling aspects, there are new measurement approaches which can be used for VPS process regulation $[9,10]$. For using and achieving an adequate soldering profile recommended by the paste manufacturers, simulation and modelling is a key investigation aspect, due to the low cost and possibility of generalisation.

Heat transient behaviour inside substrates and components can have an effect on the soldering reliability and on thermomechanical aspects of the assemblies. Our paper presents a fast explicit calculation of the one-dimensional heat distribution of standard FR4 substrate material during VPS. With the 
investigation into the heating of the base substrate, further modelling conditions can be verified; also the differences between thicknesses and applied substrates can be investigated from the aspect of even heating along the thickness of the board.

\section{Analytical Solution OF ONE- Dimensional Transient Heat Conduction}

In electronics manufacturing, the heat transient of a printed circuit board (PCB) (unassembled for simpler consideration) can be assumed as a plane wall geometry, if the thickness of the PCB is at least one magnitude smaller than the other dimensions (length and width). Therefore most electronics assembly substrates can be considered as a plane wall in horizontal alignment, which is the case in reflow soldering and VPS as well..

Figure 2 illustrates a vertically aligned plane wall geometry (cross section of a PCB) for which the transient heat conduction was investigated in this work. The vertical alignment is for graphic purposes only. $(L)$ is the half thickness of the PCB, $(x=0)$ represents the central point. From each surface, the same constant $(h)$ heat transfer coefficient is considered during the process, therefore the geometry is thermal-symmetrical around the midplane, $-\mathrm{L}<\mathrm{x}<0$ has the same transient manner as the $0<\mathrm{x}<\mathrm{L}$ region and this practically means that the temperature is going to be same at any $(t)$ time at $-\mathrm{x}$ and $+\mathrm{x}$ positions.

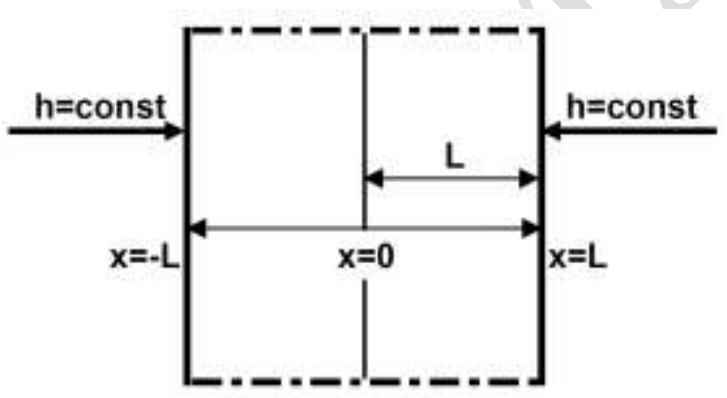

Fig. 2. Plane wall geometry (cross section of a PCB)

With the midplane thermal symmetry, the problem can be formulated for only the positive half domain $0 \leq \mathrm{x} \leq \mathrm{L}$ and applied to the other half afterwards. This work presents an implementation for calculating the heat transfer transient in a common FR4 material PCB. For this type of geometry, the following equations describe the one-dimensional heat transient conduction problem based on the work of Yunus and Cengel [11].
The one-dimensional transient conduction problem for a plane wall can be expressed with the following differential equation under the conditions of uniform initial temperature, constant heat transfer coefficient and constant thermophysical properties:

$$
\begin{gathered}
\frac{\partial^{2} T}{\partial x^{2}}=\frac{1}{\alpha} \frac{\partial T}{\partial t}, \\
\alpha=\frac{k}{\rho c_{p}}
\end{gathered}
$$

for the half domain, where $0 \leq \mathrm{x} \leq \mathrm{L}$, $\mathrm{x}$ is the actual position within the plane wall, $\alpha$ is the thermal diffusivity of the material $\left[\mathrm{m}^{2} \mathrm{~s}\right], \mathrm{k}[\mathrm{W} / \mathrm{mK}]$ is the thermal conductivity, $\rho\left[\mathrm{kg} / \mathrm{m}^{3}\right]$ is the density and $\mathrm{c}_{\mathrm{p}}[\mathrm{J} / \mathrm{kgK}]$ is the specific heat capacity.

Boundary conditions:

$$
\frac{\partial T(0, t)}{\partial x}=0 \text { and }-k \frac{\partial T(L, t)}{\partial x}=h\left[T(L, t)-T_{\infty}\right] .
$$

Initial condition:

$$
T(x, 0)=T_{i} .
$$

The differential equation can be eased from dimension by defining a dimensionless space variable:

$$
X=\frac{x}{L},
$$

and dimensionless temperature:

$$
\theta(x, t)=\frac{T(x, t)-T_{\infty}}{T_{i}-T_{\infty}} .
$$

The dimensionless solution for the differential equation of the 2L-thick plane wall geometry can be expressed as

$$
\theta=\sum_{n=1}^{\infty} \frac{4 \sin \lambda_{n}}{2 \lambda_{n}+\sin \left(2 \lambda_{n}\right)} e^{-\lambda_{n}^{2} \tau} \cos \left(\lambda_{n} \frac{x}{L}\right),
$$

where $\lambda_{n}$ 's are the roots of eq. (8)

$$
\begin{gathered}
\lambda_{n} \tan \lambda_{n}=B i, \\
B i=\frac{h L}{k},
\end{gathered}
$$

where $\mathrm{Bi}$ is the dimensionless heat transfer coefficient (Biot number), $\mathrm{L}$ is the characteristic length of a given geometry $[\mathrm{m}]$, in this case, half thickness of the plane wall.

In practical terms, eq. (7) is difficult to handle, but an approximate analytical solution for the 
dimensionless temperature, the previous plane wall geometry with one-term approximation can be expressed as:

$$
\begin{aligned}
\theta_{\text {wall }}=\frac{T(x, t)-T_{\infty}}{T_{i}-T_{\infty}} & =A_{1} e^{-\lambda_{1}^{2} \tau \cos \left(\frac{\lambda_{1} x}{L}\right)}, \tau>0.2, \\
\tau & =\frac{\alpha t}{L^{2}}=\text { Fo }
\end{aligned}
$$

where $\tau$ is the dimensionless time (Fourier number) and $\lambda_{1}$ is the first root between 0 and $\pi$ of eq. (8), and $A_{1}$ is the following (eq. (11)):

$$
A_{1}=\frac{4 \sin \left(\lambda_{1}\right)}{2 \lambda_{1}+\sin \left(2 \lambda_{1}\right)} \text {. }
$$

Approximation with only the first term of the series results in an error only under $2 \%$.

This approximation can be used in case of an FR4 PCB material since $\tau>0.2$ during the modelling. Table 1. contains the parameters of the FR4 for the calculations (for different thicknesses between $0.25 \mathrm{~mm}$ and $2 \mathrm{~mm}$ with $0.25 \mathrm{~mm}$ resolution).

TABLE I. FR4 PRINTED CIRCUIT BOARD MATERIAL PROPERTIES

\begin{tabular}{|c|c|c|}
\hline \multicolumn{3}{|c|}{ FR4 material properties } \\
\hline Density $\left[\frac{\mathrm{kg}}{\mathrm{m}^{3}}\right]$ & Heat conductivity $\left[\frac{\mathrm{W}}{\mathrm{mK}}\right]$ & Heat capacity $\left[\frac{\mathrm{J}}{\mathrm{kgK}}\right]$ \\
\hline 2100 & 0.6 & 600 \\
\hline
\end{tabular}

For the heat transfer, the specific parameters of vapour phase soldering was used. In this case, based on previous experiments on PCBs, an approximate average constant heat transfer coefficient was used with the value of $120\left[\mathrm{~W} / \mathrm{m}^{2} \mathrm{~K}\right]$ at each side of the PCB as shown in Fig. 2., an initial temperature of $\mathrm{T}_{\mathrm{i}}=25^{\circ} \mathrm{C}$ and steady state temperature $\mathrm{T}_{\infty}=170^{\circ} \mathrm{C}$ (which is the boiling point of Galden HT170) were used. This type of Galden is especially relevant for solder alloy with low melting point, e.g. $\mathrm{Bi}_{42} \mathrm{Sn}_{58}\left(138^{\circ} \mathrm{C}\right)$. The PCB materials, VPS fluids, and even heat transfer methods can be easily extended for future investigations.

\section{RESUlTS AND DISCUSSION}

To apply the approximate solution for the investigated PCB, several parameters should be determined.

$\lambda_{1}$ was determined with Excel Solver add-on using Generalized Reduced Gradient (GRG) Nonlinear solving method. To get $\lambda_{1}$, eq. (8) was sorted to zero, then the solver then was parametrized with solving the equation as a function of $\lambda_{1}$. The PCB's Biot number was calculated based on the parameters from Table I and eq. (9). After the determination of $\lambda_{1}$, eq. (10) can be solved explicitly together with eq. (12).

The calculated temperature changes of the surface and midplane position of an FR4 board with $2 \mathrm{~mm}$ total thickness is shown in time domain in Fig. 3. (starting from 0.5 second) for the first 27.5 seconds of the VPS process.

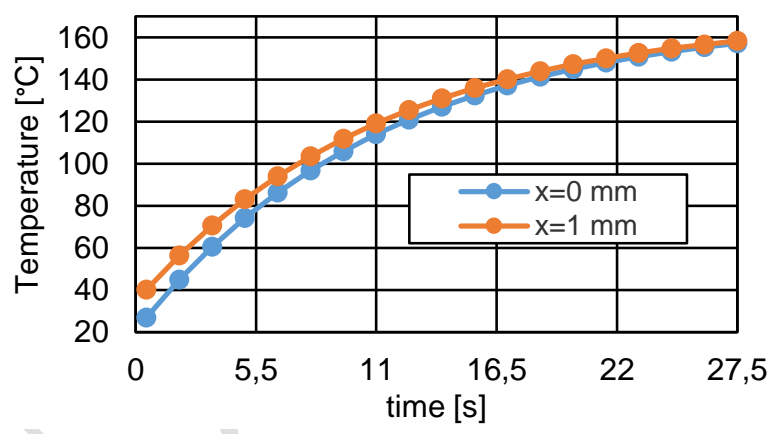

Fig. 3. Temperature of the surface $(x=1 \mathrm{~mm})$ and the midplane $(\mathrm{x}=0 \mathrm{~mm})$ during VPS

It can be seen that the temperature of the surface is always higher during the soldering (as expected). The temperature differences for all of the investigated thickness values are discussed later. Calculated heat distribution for the $2 \mathrm{~mm}$ thick FR4 are illustrated in Figure 4.

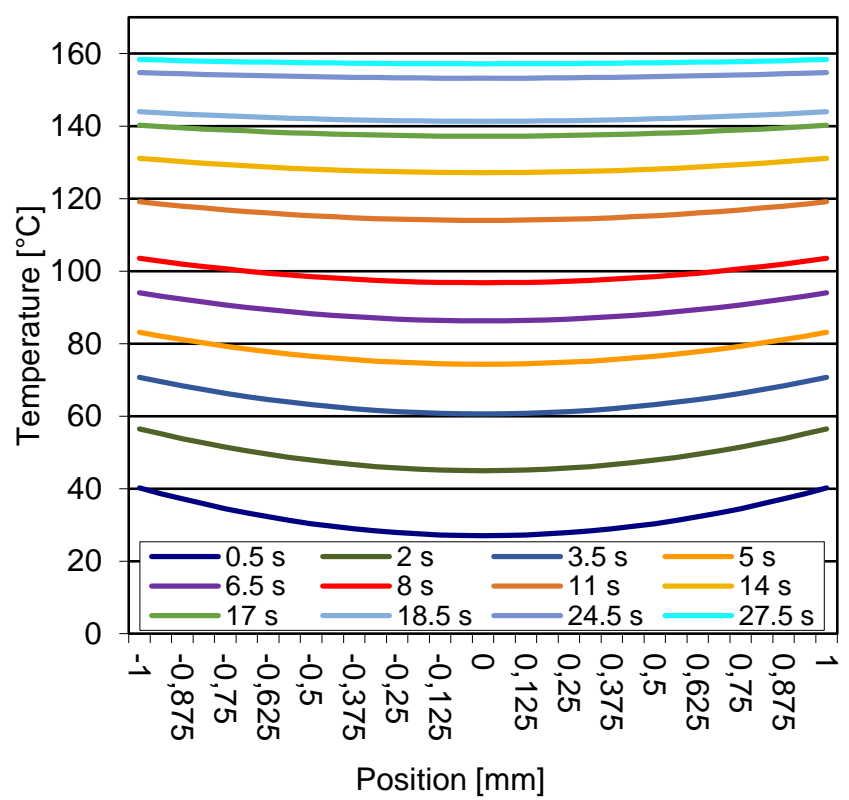

Fig. 4. Temperature distribution alongside the PCB thickness $(2 \mathrm{~mm})$ at different times during VPS 
The temperature distribution was shown at twelve selected time stamps in the modelled VPS process. It can be seen that after 0.5 seconds from the start of the condensation, the temperature difference on the surface $(\mathrm{x}= \pm 1 \mathrm{~mm})$ and the midplane $(\mathrm{x}=0)$ is approximately $13{ }^{\circ} \mathrm{C}$. The other thickness values are not illustrated individually since they show the same behaviour (but smaller temperature differences). Figure 5. contains the temperature difference of the surface and the midplane for the modelled process in time domain for the investigated thickness range. The temperature difference is proportional with the thickness of the PCB board (the higher the thickness, the greater the difference is).

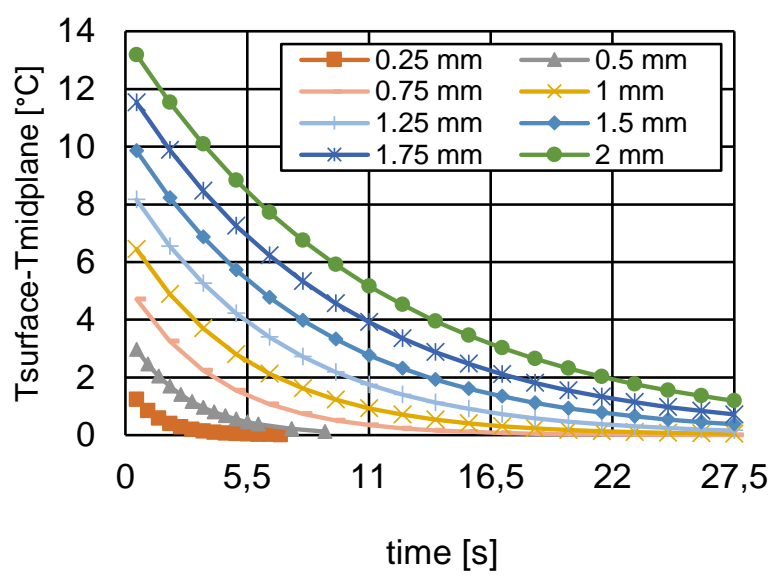

Fig. 5. Temperature difference between the surface and the midplane during the modelled VPS process for different PCB thicknesses

It can be seen that the investigated $0.25 \mathrm{~mm}$ to $2 \mathrm{~mm}$ thickness scale has really different temperature difference values between the surface and the midplane. After 2 seconds of the start of the process the temperature difference varies from approximately $1.7^{\circ} \mathrm{C}$ to $11.5^{\circ} \mathrm{C}$. From the aspect of soldering quality, the temperature difference when the melting point is reached $\left(\mathrm{Bi}_{42} \mathrm{Sn}_{58}, 138{ }^{\circ} \mathrm{C}\right)$ is the most critical. Fig. 6 . shows the time to reach melting point for each thickness value. The results vary between approximately 1 second and 8 seconds. Fig. 7. presents the temperature difference of the surface and the midplane when the melting point is reached.

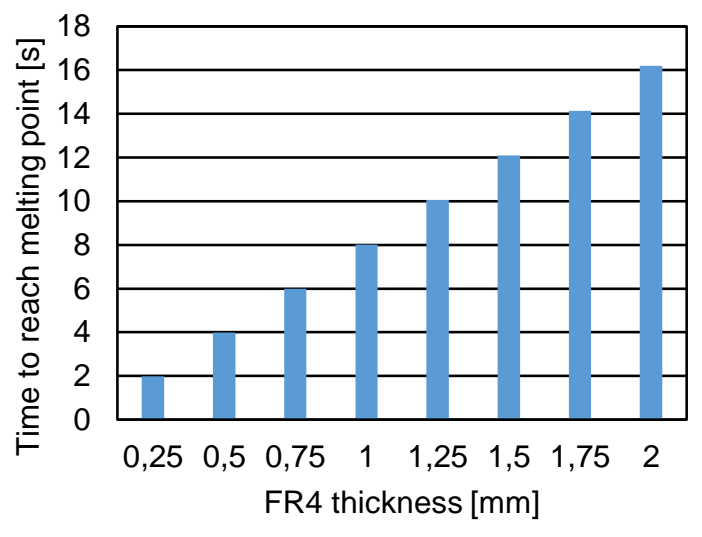

Fig 6. Elapsed time to reach melting point $\left(138^{\circ} \mathrm{C}\right)$ for different PCB thickness values

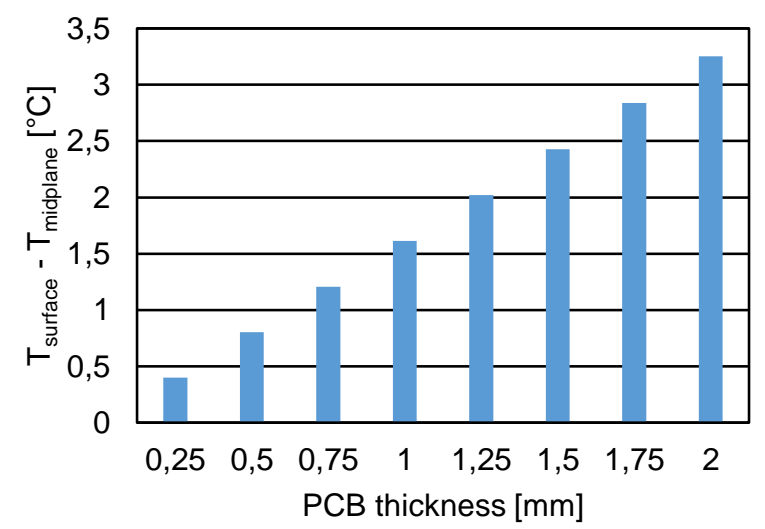

Fig. 7. Temperature difference at the melting point $\left(138^{\circ} \mathrm{C}\right)$

The modelled results for the temperature differences have values from approximately $0.4{ }^{\circ} \mathrm{C}$ to $3.25{ }^{\circ} \mathrm{C}$ in the investigated thickness scale. These values do not mean significant risk from the aspect of soldering quality. Also the risk of CTE mismatch along the FR4 structure (in a possible multi-layer configuration) is minimal in such cases.

This shows, that (in reflow terms) with a relative high heat transfer value on the PCB, the process does not pose risks regarding high temperature gradients along the thickness/vertical structure of the PCB.

\section{Conclusions}

In this paper the heat distribution within printed circuit boards was investigated during standard vapour phase soldering process. In the cases where the PCB thickness is at least one magnitude smaller than the other dimensions, it can be considered as plane wall 
geometry (usual case for PCBs) in horizontal alignment.

The heat distribution results show that with a typical standard VPS setup, the temperature differences within the material (between surface and center) does not have significant differences. This means, that explicit, one cell modelling of PCBs might be performed and continued in the future with insignificant error.

The results showed that for Galden HT170, FR4 boards with thickness value not greater than $2 \mathrm{~mm}$, the temperature difference between the surface and the midplane of the substrate is less than $3.5^{\circ} \mathrm{C}$. (Considering the melting point of low temperature alloys (e.g. $138^{\circ} \mathrm{C}$ ).)- This does not mean a significant risk for the soldering quality, originating from e.g. a mismatch in the coefficients of thermal expansion along the PCB structure. VPS performs well even with the material parameters of the FR4 construction, which is considered to have weaker thermal parameters compared to e.g. ceramic substrates. Further PCB materials with better thermal diffusivity might perform even better with the given VPS configuration.

In the future, several different materials (e.g. ceramics) and thicknesses can be investigated with this same methodical approach, with focus on different alloy melting points as well. Besides the different materials and thickness values, the modelling can be even extended for other reflow soldering methods such as infrared-radiation or convection (with relevant specific heat transfer coefficients). Literature shows [12], that IR or convection based soldering have considerably different heat transfer coefficient values, this fact might also alter the significance of temperature differences inside a printed circuit board substrate.

Furthermore the use of Galden with higher boiling point temperature (e.g. $230{ }^{\circ} \mathrm{C}$ ) might increase the differences to a more significant level, where the temperature overshoots the glass transition temperature of the epoxy material inside the FR4 PCB.

\section{ACKNOWLEDGEMENT}

The paper and the research is partially supported by by the National Research, Development and Innovation Office - NKFIH, FK 127970 and the Bolyai János Scholarship and Bolyai+ (ÚNKP-18-4-BME-321).

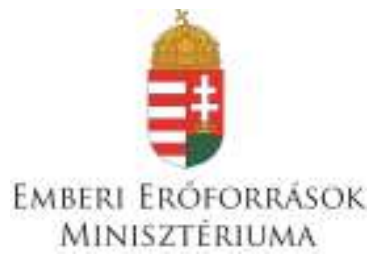

\section{REFERENCES}

[1] Olivér Krammer, (2014) "Comparing the reliability and intermetallic layer of solder joints prepared with infrared and vapour phase soldering", Soldering \& Surface Mount Technology, Vol. 26 Issue: 4, pp.214222, doi: 10.1108/SSMT-09-2013-0023

[2] Solvay - Galden types and properties, https://www.solvay.com/en/products/brands/galdenpfpe, (Accessed at 26.03.2019.)

[3] Claus Zabel: Condensation Reflow Soldering - The Soldering Process with Solutions for future Technological Demands, ASSCON

[4] B. Illés (2013) "Modeling Galden layer formation on PCB surface during Vapour Phase Soldering," 2013 IEEE 19th International Symposium for Design and Technology in Electronic Packaging (SIITME), Galati, pp. 69-74. doi: 10.1109/SIITME.2013.6743646

[5] Lijuan Huang, Zhenghu Zhu, Hiarui Wu, Xu Long, (2019) "Board-level vapor phase soldering (VPS) with different temperature and vacuum conditions", Multidiscipline Modeling in Materials and Structures, Vol. 15 Issue: 2, pp.353-364. doi: 10.1109/SIITME.2013.6743646

[6] Barbara Dziurdzia, Maciej Sobolewski, Janusz Mikolajek, (2018) "Convection vs vapour phase reflow in LED and BGA assembly", Soldering \& Surface Mount Technology, Vol. 30 Issue: 2, pp.87-99. doi: 10.1108/SSMT-10-2017-0031

[7] S. Lüngen, A. Klemm and H. Wohlrabe (2015) "Evaluation of the quality of SMDs according to vacuum vapour phase soldering," 2015 38th International Spring Seminar on Electronics Technology (ISSE), Eger, pp. 218-222. doi: 10.1109/ISSE.2015.7247993

[8] Petr Veselý, Eva Horynová, Jiří Starý, David Bušek, Karel Dušek, Vít Zahradník, Martin Plaček, Pavel Mach, Martin Kučírek, Vladimír Ježek, Milan Dosedla, (2018) "Solder joint quality evaluation based on heating factor", Circuit World, Vol. 44 Issue: 1, pp.37-44. doi: 10.1108/CW-10-2017-0059

[9] Lubomir Livovsky, Alena Pietrikova, (2019) "Measurement and regulation of saturated vapour height level in VPS chamber", Soldering \& Surface Mount Technology, doi: 10.1108/SSMT-10-2018-0040

[10] Lubomir Livovsky Alena Pietrikova (2017), Real-time profiling of reflow process in VPS chamber, Solder. Surf. Mt. Tech, Vol. 29 Iss 1., doi: 10.1108/SSMT-102016-0026 
[11] Y. A. Çengel, A. J. Ghajar (2015), Heat and Mass

Transfer, 5th Edition, Grawhil Education, pp. 245-250
[12] Wolfgang Leider, Dampfphasenlöten, Grundlagen und praktische Anwendung, Eugen G Leuze Verlag, 2002, pp 37. 